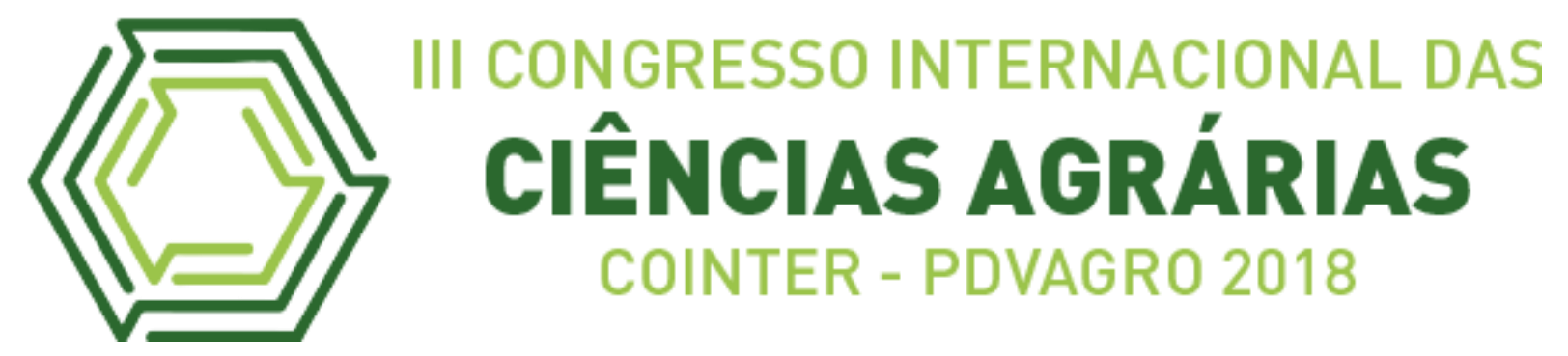

\title{
EXPERIÊNCIA NA REALIZAÇÃO DE MANEJOS EM SISTEMA AGROFLORESTAL
}

\section{EXPERIENCE IN MANAGING AGROFORESTRY SYSTEMS}

\author{
Apresentação: Relato de Experiência \\ Robson Vinício dos Santos ${ }^{1}$; Mércia Cardoso da Costa Guimarães ${ }^{2}$; Marta Xavier de \\ Carvalho Correia ${ }^{3}$, Paulo Márcio Barbosa de Arruda Leite ${ }^{4}$ \\ DOI: https://doi.org/10.31692/2526-7701.IIICOINTERPDVAGRO.2018.00733
}

\section{Introdução}

Os sistemas agroflorestais visam contribuir para a solução de problemas no uso dos recursos naturais, por suas funções biológicas e socioeconômicos. A presença de árvores no sistema traz benefícios diretos e indiretos, como o controle da erosão, manutenção da fertilidade do solo, o aumento da biodiversidade, a diversificação da produção e o alongamento do ciclo de manejo de uma área (ENGEL, 1999). Este tipo de sistema tenta reproduzir ao máximo a arquitetura das formações naturais, para melhor aproveitar a radiação, umidade e nutrientes (NARDELE e CONDE, 2010).

Objetivou-se demonstrar a importância da realização de técnicas como poda, cobertura orgânica, nutrição do solo e capinação no Sistema Agroflorestal (SAF) desenvolvidas durante o estágio no Serviço de Tecnologia Alternativa (SERTA), onde são de grande importância para o conhecimento dos pequenos produtores rurais, por trazer uma perspectiva sustentável, possibilitando uma produção diversificada e lucrativa, sem comprometer as características nutricionais do solo em que está sendo trabalhado.

\section{Relato de Experiência}

O SERTA é uma Organização da Sociedade Civil de Interesse Público (OSCIP) que desenvolve atividades agroecológicas e que trabalha muito no âmbito da sustentabilidade familiar. Nela, realizou-se o estágio curricular obrigatório para conclusão do curso Técnico

\footnotetext{
${ }^{1}$ Agropecuária, IFPE - Campus Vitória de Santo Antão, robson4651@hotmail.com

${ }^{2}$ Professora, IFPE - Campus Vitória de Santo Antão, mercia.guimaraes@vitoria.ifpe.edu.br

${ }^{3}$ Professora, IFPE - Campus Vitória de Santo Antão, marta.xavier@vitoria.ifpe.edu.br

${ }^{4}$ Professor, Serviço de Tecnologia Alternativa - SERTA, paulomarcio@serta.org.br
} 
em Agropecuária por um período de dois meses consecutivos.

Foram desenvolvidas diversas atividades relacionadas ao SAF, que se trata de um sistema bastante complexo e visa representar a mesma metodologia de desenvolvimento das culturas no meio natural, sem uso de defensivos químicos. Necessita-se de manejos específicos para manter este sistema funcional e no estágio foram desenvolvidas alguns deles, podendo-se destacar a poda, cobertura orgânica, nutrição do solo e capinação.

Todos estes manejos foram realizados com a função de possibilitar o equilíbrio do sistema para que, posteriormente, venha a se obter os resultados esperados no solo, com o objetivo de manter uma área propícia para ser cultivada a longo prazo, bem como garantir uma boa produção de hortaliças, fruteiras e tubérculos que foram os alimentos cultivados no SAF do SERTA e produzidos para fins de consumo próprio e comercialização.

Inicialmente, realizou-se a prática da poda que consiste na retirada do excesso de biomassa presente nas leguminosas que, por possuírem um porte maior, estavam diminuindo a luminosidade solar sobre as outras culturas de porte médio ou rasteiro, desfavorecendo a atividade fotossintética das mesmas e reduzindo seu desenvolvimento.

Utilizou-se tesoura de pressão para cortar os galhos com diâmetros maiores (Imagem 1A) e o facão para caules finos ou herbáceos. O corte foi realizado na diagonal para impossibilitar o acúmulo de água. Em seguida, produziu-se um macerado (pasta derivada da calda bordalesa) que consiste em uma mistura de cal virgem ou hidratado e sulfato de cobre, que foi colocada no corte da poda (Imagem 1B), servindo como fungicida, evitando que algum parasita penetre no local podado.

As folhas retiradas nesta atividade foram utilizadas como cobertura orgânica sobre os canteiros, com a finalidade de devolver ao solo todos os nutrientes absorvidos no desenvolvimento da cultura, diminuir a incidência dos raios solares e manter a temperatura interna do solo, ajudando na habitação da microfauna presenta na sua estrutura. Além dessas folhas provenientes das podas, utilizou-se também Capim Elefante (Pennisetum purpureum) triturado na máquina (Imagem 1C), ajudando a uniformizar todos canteiros.

Percebe-se que a nutrição do solo também é realizada no momento da cobertura. Sobretudo, há outras técnicas que foram utilizadas com essa mesma finalidade, como o composto (Imagem 1D) e o pó de rocha (Imagem 1E), pois, esse é um sistema bastante cauteloso onde todas as culturas se interligam e se beneficiam simultaneamente, por isso é bastante equilibrado. 
A capinação (Imagem 1F) foi realizada com o intuito de retirar o excesso de Tiririca (Cyperus haspan) e outras espécies de plantas que competiam com as culturas, interferindo no seu desenvolvimento.

Imagem 1: A - Poda para evitar o sombreamento excessivo. B Aplicação de macerado para evitar a entrada de patógenos. C Trituração do capim para cobertura orgânica. D - Produção de composto para adubar os canteiros. E - Aplicação de pó de rocha para nutrir os canteiros. F - Realização de capinação para evitar competição entre as culturas. Fonte: Própria.
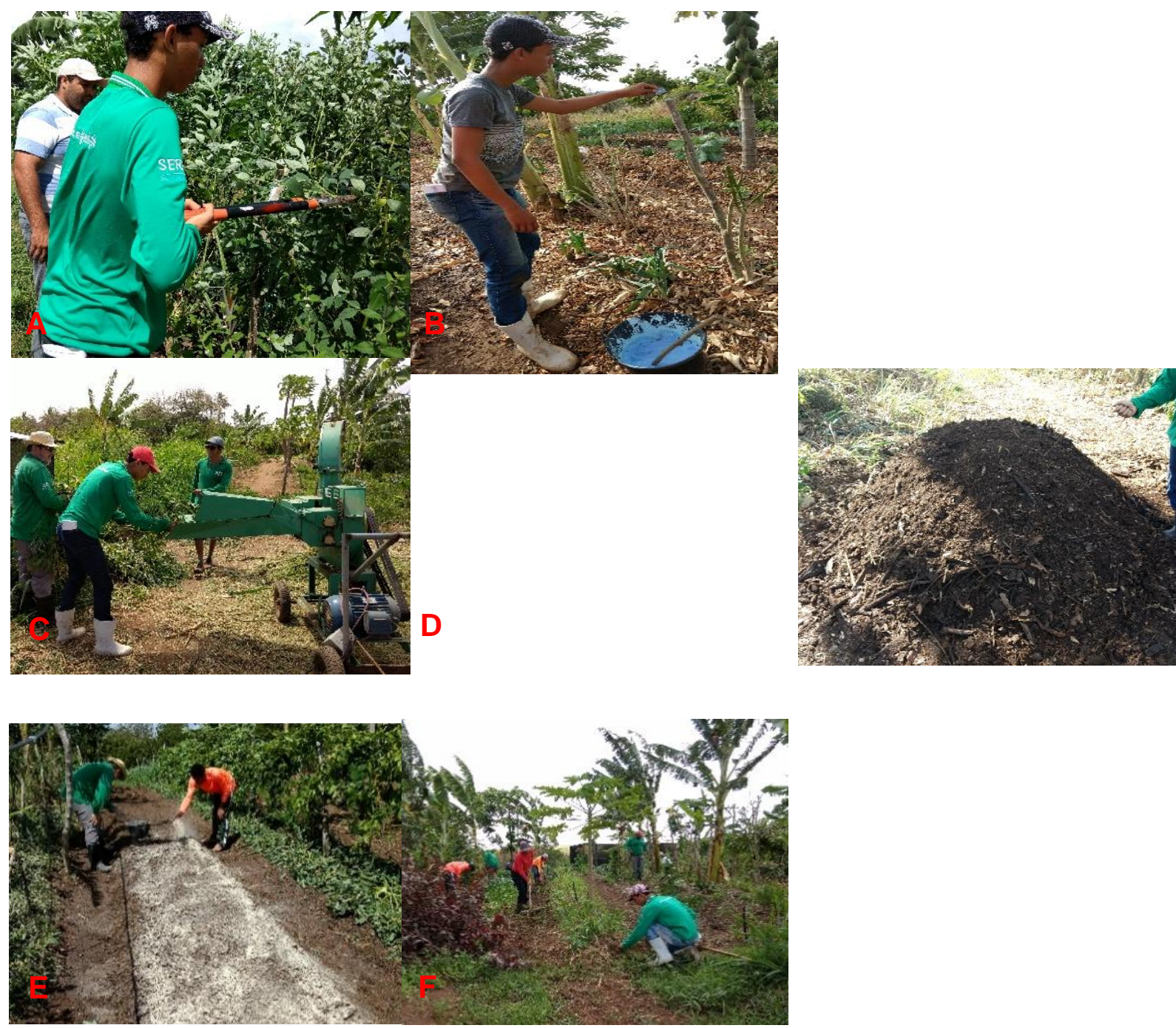

\section{Considerações}

As atividades desenvolvidas neste estágio, especificamente no Sistema Agroflorestal, foram importantes para o entendimento de que é possível se obter uma produção anual e diversificada sem a utilização de quaisquer defensivos agrícolas, conservando muito bem os recursos nutricionais do solo, possibilitando o pequeno produtor a trabalhar nesta área por um 
longo tempo com um bom lucro derivado da comercialização dos produtos.

Esta viabilidade pode ser alcançada com a realização dos manejos práticos que foram desenvolvidos como a poda, a retirada de ervas daninhas próximas as culturas, diversificação dos canteiros, nutrição do solo, adição de cobertura orgânica, entre outras inúmeras atividades, sempre buscando equilibrar a produção e os recursos do solo.

As atividades desenvolvidas foram de suma importância para ampliar conhecimentos, bem como, me profissionalizar neste âmbito da agroecologia como técnico agrícola e pela ótima experiência de trabalhar em conjunto com outras pessoas de diversas etnias.

\section{Referências}

ENGEL, V.L 1999 - SISTEMAS AGROFLORESTAIS: CONCEITOS E APLICAÇÕES, disponível em: http://saf.cnpgc.embrapa.br/publicacoes/01.pdf - Acesso em: 20/07/2018.

NARDELE, M; CONDE, I., 2010 - APOSTILA SISTEMA AGROFLORESTAIS disponível em: https://biowit.files.wordpress.com/2010/11/apostila-agroflorest.pdf - Acesso em: 20/07/2018. 